\title{
Impact of asynchronous ovulations on the expression of sex-dependent growth rate in bovine preimplantation embryos
}

\author{
B. Avery \\ Department of Reproduction, Royal Veterinary and Agricultural University, Bülowsvej 13, \\ DK-1870 Frederiksberg C, Denmark
}

\begin{abstract}
Summary. In cattle, male embryos have a faster growth rate than female embryos, and this results in alteration of the normal 1:1 sex ratio in embryos divided into three developmental groups. The fastest developed one-third are predominantly males, the slowest one-third predominantly females, and in the intermediate one-third no alteration of the sex ratio is seen, However, the deviations of the sex ratios are only $15-20 \%$ from random. These findings are compatible with the assumption that, in superovulated cows, ovulations follow a normal distribution and that, at the time of sampling at Day 7 , male and female embryos differ with regard to development by 1 or $2 \mathrm{~h}$. Because of this it is unlikely that larger changes in the sex ratios can be expected.
\end{abstract}

Keywords: ovulation; sexing; embryo development; relative growth; cow

\section{Introduction}

In superovulated and artificially inseminated dairy cattle, uterine flushings sometimes result in embryos of different cleavage stages within the same animal. The main explanations for this phenomenon are asynchronous ovulations, variations in fertilization times and/or inherent differences in the cleavage rates of the embryos.

The cleavage rates have been shown to be sex-dependent in mouse embryos (Tsunoda et al., 1985; Seller \& Perkins-Cole, 1987) in such a way that the most developed one-third of the embryos within a flushing were predominantly males, the least developed one-third predominantly females and in the middle one-third no sex effect could be demonstrated. This sex effect was also shown to be present in bovine embryos (Itoh \& Goto, 1986; Avery et al., 1989a, b).

The results of Itoh \& Goto (1986) were based on 49 calves, born from embryos which had been divided into three developmental groups before transfer to recipients. The sex ratios from the fast, intermediate and slow groups of development were $77 \%, 40 \%$ and $23 \%$ respectively. Avery et al. (1989b) retrospectively examined 139 flushings from dairy cattle, and found that in $23 \%$ of the flushings the embryos could be divided into three developmental groups: 63 calves were born following transfer of fresh embryos, resulting in sex ratios of $62 \%, 58 \%$ and $32 \%$ in the fast, intermediate and slow groups, respectively. These results were not significantly different from a 1:1 sex ratio according to strict evaluations $\left(\chi^{2}, P<0.084\right)$. In $21 \%$ of the flushings only two developmental groups were seen, resulting in 23 calves from transfer of fresh embryos, with sex ratios of $57 \%$ and $44 \%$ from the fast and slow groups, respectively.

In this paper we suggest a theoretical model describing the dependence between this sex effect and the impact of the ovulation pattern in superovulated dairy cattle, under the assumption that, except for a faster growth rate for male embryos, all other conditions for the two sexes are equal. 


\section{Results}

Since ovulation in superovulated cattle is asynchronous and takes place over approximately $10 \mathrm{~h}$ (Callesen et al., 1986), and since an equal probability for fertilization with $\mathrm{X}$ and $\mathrm{Y}$ chromosomebearing spermatozoa can be assumed, it is not to be expected that the sex effect from differences in cleavage rates will exceed a certain value. Therefore in a model explaining the results seen in practice the distribution pattern of the ovulations must be the key. Since in biology many observations follow a normal distribution, we re-evaluated previous embryo culture experiments, in order to see whether the growth pattern for the embryos was consistent with a normal distribution.

Development of the embryos, which were obtained following superovulation and artificial insemination, was evaluated every $1-2 \mathrm{~h}$ during the culture period (details given by Avery et al., 1989a; Avery \& Schmidt, 1989). The embryos were predominantly at the compact morula stage at collection, and the following stages of development were noticed during culture: compact morula (blastomeres forming a compact mass); young blastocyst (a fluid-filled cavity begins to form between the blastomeres); blastocyst (prominent fluid-filled cavity, differentiation into outer trophoblast layer and inner cell mass); expanded blastocyst (increase in the embryonic diameter). However, since it was not possible to know where in the compact morula interval an embryo would be at collection, whereas it was possible to identify the time when an embryo reached the young blastocyst stage, the transition between young blastocyst to blastocyst was used as the marker for determination of the growth pattern. Of 45 embryos from 4 different flushings which reached the young blastocyst stage during culture, all developed to at least the blastocyst stage. By plotting on probit paper it was seen that the results fitted into a normal distribution with a standard deviation of $3 \mathrm{~h}$, meaning that $95 \%$ of the embryos would develop from the young blastocyst to the blastocyst stage within $12 \mathrm{~h}$ (Table 1 ).

Table 1. Cumulative distribution of 45 bovine embryos cultured from the young blastocyst to the blastocyst stage

\begin{tabular}{lrr}
\hline \multirow{2}{*}{$\begin{array}{l}\text { Time in culture } \\
\text { (h) }\end{array}$} & \multicolumn{2}{c}{ Blastocysts } \\
\cline { 2 - 3 } & No. & $\%$ \\
\hline 1 & 9 & 20 \\
2 & 13 & 29 \\
3 & 21 & 47 \\
4 & 28 & 62 \\
5 & 29 & 64 \\
6 & 38 & 84 \\
7 & 40 & 89 \\
8 & 41 & 91 \\
9 & 42 & 93 \\
14 & 43 & 96 \\
15 & 45 & 100 \\
\hline
\end{tabular}

We are aware of the fact that a growth pattern compatible with a normal distribution has only been shown in the interval young blastocyst-blastocyst, nevertheless we will assume that embryo development in the whole interval from fertilization to expanded blastocysts follows the same type of growth pattern.

In our model we also assume that the ovulations follow a normal distribution. For calculations of the theoretical sex ratios a series of graphs were constructed on probit paper, letting the standard deviations vary from 1 to $4 \mathrm{~h}$ (not shown). 
Since fertilizations are likely to have approximately equal probabilities of resulting in a male or a female zygote, the ovulation distributions for males and females must be identical. At the beginning the two distributions coincide. With time the two distributions separate, and at the time of embryo collection at Day 7 we presume a 1,2 or $3 \mathrm{~h}$ developmental difference between them. This is followed by division into 2 or 3 developmental groups and calculation of the corresponding sex ratios, which are compared with the results found in practice.

Table 2. Theoretical distribution and sex ratios for male and female embryos with a 2 -h difference between males and females, and a standard deviation for ovulations of $2 \mathrm{~h}$

\begin{tabular}{|c|c|c|c|c|c|c|}
\hline \multirow[b]{2}{*}{ Hours } & \multicolumn{2}{|c|}{$\%$ Ovulations } & \multicolumn{2}{|c|}{$\begin{array}{l}\text { Ranked after relative } \\
\text { developmental age }\end{array}$} & \multicolumn{2}{|c|}{ Sex ratio $\%$} \\
\hline & Cumul & er hour & $\%$ Male & $\%$ Female & 3 groups & 2 groups \\
\hline 0 & 0 & 0 & & & & \\
\hline 2 & 2 & 2 & 2 & 2 & & \\
\hline 3 & 7 & 5 & 5 & 5 & & \\
\hline 4 & 16 & 9 & 9 & 9 & 76 & 68 \\
\hline 5 & 32 & 16 & 16 & 16 & & \\
\hline 6 & 50 & 18 & 18 & 18 & & \\
\hline 7 & 70 & 20 & 20 & 20 & 50 & \\
\hline 8 & 84 & 14 & 14 & 14 & & \\
\hline 9 & 94 & 10 & 10 & 10 & & \\
\hline 10 & 98 & 4 & 4 & 4 & & \\
\hline 12 & 100 & 2 & 2 & 2 & 24 & 32 \\
\hline
\end{tabular}

Table 2 shows the theoretical distributions for male and female embryos at the time of embryo collection on Day 7 for a 2-h difference between males and females and a standard deviation of $2 \mathrm{~h}$ for ovulations. The embryos are arranged according to their relative developmental age with males and females of the same relative age grouped together, followed by division into 3 versus 2 groups of approximately equal sizes.

Table 3 shows the sex ratios predicted for developmental differences of 1,2 and $3 \mathrm{~h}$ and standard deviations of $1,2,3$ and $4 \mathrm{~h}$ for ovulations.

\section{Discussion}

Several of the calculations in Table 3 fit with the data given by Avery et al. (1986b) in which 63 calves born from embryos, which could be divided into three developmental groups resulted in sex ratios of $62 \%, 58 \%$ and $32 \%$, and 25 calves from embryos divided into two groups gave sex ratios of $57 \%$ and $44 \%$.

Our results are consistent either with a $1 \mathrm{~h}$ developmental difference between males and females at Day 7, and standard deviations for ovulations between 1.5 and $2 \mathrm{~h}$ meaning that $95 \%$ of the ovulations occur within $6-8 \mathrm{~h}$, or with a 2 -h developmental difference and standard deviations for ovulations of 3 and $4 \mathrm{~h}$. The sex ratios from embryos divided into 2 or 3 groups corresponded with the theoretical sex ratios.

The results of Itoh \& Goto (1986), who found sex ratios of $77 \%, 40 \%$ and $23 \%$ among 49 calves divided into three developmental groups, fit distributions in which the standard deviation of ovulation equals the time difference between male and female development. 
Table 3. Theoretical distributions of sex ratios for developmental differences of 1,2 and $3 \mathrm{~h}$ and standard deviations for ovulations of $1,2,3$ and $4 \mathrm{~h}$

\begin{tabular}{|c|c|c|c|c|c|c|}
\hline \multirow{3}{*}{$\begin{array}{l}\text { Standard } \\
\text { deviation } \\
\text { (h) }\end{array}$} & \multicolumn{6}{|c|}{ Developmental differences in sex ratio \% } \\
\hline & \multicolumn{2}{|c|}{$1 \mathrm{~h}$} & \multicolumn{2}{|c|}{$2 \mathrm{~h}$} & \multicolumn{2}{|c|}{$3 \mathrm{~h}$} \\
\hline & 3 groups & 2 groups & 3 groups & 2 groups & 3 groups & 2 groups \\
\hline 1 & $\begin{array}{l}76 \\
50 \\
24\end{array}$ & 67 & $\begin{array}{r}91 \\
50 \\
8\end{array}$ & 84 & $\begin{array}{r}100 \\
53 \\
3\end{array}$ & $\begin{array}{r}92 \\
8\end{array}$ \\
\hline 2 & $\begin{array}{l}64 \\
50 \\
35\end{array}$ & $\begin{array}{l}60 \\
40\end{array}$ & $\begin{array}{l}78 \\
50 \\
24\end{array}$ & 32 & $\begin{array}{l}83 \\
50 \\
15\end{array}$ & $\begin{array}{l}76 \\
24\end{array}$ \\
\hline 3 & $\begin{array}{l}58 \\
50 \\
43\end{array}$ & $\begin{array}{l}56 \\
44\end{array}$ & $\begin{array}{l}67 \\
49 \\
34\end{array}$ & 38 & $\begin{array}{l}76 \\
48 \\
26\end{array}$ & $\begin{array}{l}68 \\
32\end{array}$ \\
\hline 4 & $\begin{array}{l}57 \\
48 \\
44\end{array}$ & 56 & $\begin{array}{l}64 \\
49 \\
38\end{array}$ & 60 & $\begin{array}{l}71 \\
50 \\
32\end{array}$ & 67 \\
\hline
\end{tabular}

The expression of sex-dependent development is in practice limited by the fact that ovulations are asynchronous, and thus continue for some hours. This implies that the sex effect will never exceed a certain value. Probably the theoretical sex ratios for dairy cattle will be very near to those we have suggested: $64 \%, 50 \%$ and $35 \%$. The results we found correspond well with an ovulation pattern described by an ideal normal distribution with a standard deviation of ovulations of $2 \mathrm{~h}$ and a developmental time difference between male and female embryos of $1 \mathrm{~h}$ at Day 7 , meaning that $95 \%$ of the ovulations occur within $8 \mathrm{~h}$ and $99.7 \%$ within $12 \mathrm{~h}$.

This could be a reasonable assumption according to Callesen et al. (1986), who found that most ovulations occurred within $10 \mathrm{~h}$. The data of Callesen et al. (1986) were based on ovariectomy of 68 superovulated dairy cattle at $24-83 \mathrm{~h}$ after prostaglandin injection. In addition the LH peak was determined. The onset of ovulations occurred $50 \mathrm{~h}$ after prostaglandin injection or $24 \mathrm{~h}$ after the LH peak, and practically all ovulations $(>90 \%)$ had occurred at $33 \mathrm{~h}$ after the LH peak. It was not possible to observe the ovulations continuously since each animal could only be subjected to one ovariectomy at a given time. This means that animals with early and late onset of ovulations must have been included, and this would have given an overestimation of the actual time interval for ovulations.

In a single flushing the sex effect will seem to be weak or not present at all, since the total number of embryos per flushing is very variable and since an early ovulated 'female' embryo may be more developed than a late ovulated 'male' embryo. This means that the chance for predicting the right sex is approximately $15-20 \%$ better in the slow and fast groups than by a random guess. On the basis of the theoretical model it seems unlikely that sex differences greater than $15-20 \%$ can be obtained. Nevertheless, although the sex dependence in developmental rates of embryos is masked by the normal distribution of the ovulations, it seems to be a real effect. It is not only of interest because it indicates that the differentiation of male and female embryos is initiated much earlier than had been thought, but is also potentially useful as a method of non-invasive sexing.

How and why this sex-dependent developmental difference functions, and when it begins is unclear. However, the only reason we can imagine why sex and growth should be connected at this early stage has to do with the sex differentiation of the male embryo. Since the sex-dependent growth rate has been demonstrated before any gonadal differentiation and hence sex hormone production is present, and also before $\mathrm{X}$-chromosome inactivation has taken place (Epstein et al., 1978; Kratzer \& Gartler, 1978; Monk \& Harper, 1978), it is likely to be due to an effect initiated and 
regulated by the $\mathrm{Y}$ chromosome. We think that since the maternal genome controls the bovine embryo until the 8-cell block (Camous et al., 1986), the sex effect will not be exerted until the embryonic genome takes over the control, which means that at embryo collection on Day 7 the sex effect has been operative for not more than 3 days.

The sex effect is also seen after implantation in mice (Seller \& Perkins-Cole, 1987): when Day-9 mice were ranked according to somite number, followed by sex chromatin determination of the yolk sac, the sex effect was very pronounced since the sex ratios were $94 \%, 45 \%$ and $25 \%$ in the fast, intermediate and slow groups of development respectively.

Mittwoch $(1983,1985)$, who has substantiated a faster growth rate of male than of female rat and human gonads, suggests that genes on the $\mathrm{Y}$ chromosome act as growth enhancers, resulting in testes growing faster than ovaries, and leading to sexual differentiation of the testes.

It is possible that a sex effect is active during the whole of pregnancy, since mammalian male fetuses grow faster than female fetuses and are on average heavier at birth.

This study was supported by The Animal Biotechnology Research Centre.

\section{References}

Avery, B. \& Schmidt, M. (1989) Sex determination of bovine embryos using $\mathrm{H}-\mathrm{Y}$ antibodies. Acta vet. scand. 30, (in press).

Avery, B., Schmidt, M. \& Greve, T. (1989a) Sex determination of bovine embryos based on embryonic cleavage rates. Acta vet. scand. 30, (in press).

Avery, B., Bak, A. \& Schmidt, M. (1989b) Differential cleavage rates and sex determination in bovine embryos. Theriogenology 32, 139-147.

Callesen, H., Greve, T. \& Hyttel, P. (1986) Preovulatory endocrinology and oocyte maturation in superovulated cattle. Theriogenology 25, 71-86.

Camous, D., Kopecny, V. \& Flechon, J.-E. (1986) Autoradiographic detection of the earliest stage of $\left[{ }^{3} \mathrm{H}\right]-$ uridine incorporation into the cow embryo. Biol. Cell 58, $195-200$.

Epstein, C.J., Smith, S., Travis, B. \& Tucker, G. (1978) Both $\mathrm{X}$ chromosomes function before visible $\mathrm{X}$ chromosome inactivation in female mouse embryos. Nature, Land. 247, 500-502.

Itoh, S. \& Goto, T. (1986) Sex frequency of offspring from different developmental stage of cattle embryos. Jap. J. Anim. AI Res. 8, 95-99.
Kratzer, P.G. \& Gartler, S.M. (1978) HGPRT activity changes in preimplantation embryos. Nature, Lond. 274, 503-504.

Mittwoch, U. (1983) Heterogametic sex chromosomes and the development of the dominant gonad in vertebrates. Am. Nat. 122, 159-180.

Mittwoch, U. (1985) Males, females and hermaphrodites. Ann. Hum. Genet. 50, 103-121.

Monk, M. \& Harper, M. (1978) X-chromosome activity in preimplantation mouse embryos from XX and XO mothers. J. Embryol. exp. Morph. 46, 53-64.

Seller, M.J. \& Perkins-Cole, K.J. (1987) Sex difference in mouse embryonic development at neurulation. $J$. Reprod. Fert. 79, 159-161.

Tsunoda, Y., Tokunaga, T. \& Sugie, T. (1985) Altered sex ratio of live young after transfer of fast- and slow-developing mouse embryos. Gamete Res. 12, 301-304.

Received 2 March 1989 